\title{
Nucleolar localization of influenza A NS1: striking differences between mammalian and avian cells
}

Romain Volmer ${ }^{1,2^{*}}$, Beryl Mazel-Sanchez ${ }^{1,2,3}$, Christelle Volmer ${ }^{1,2}$, Sébastien M Soubies ${ }^{1,2}$, Jean-Luc Guérin ${ }^{1,2}$

\begin{abstract}
In mammalian cells, nucleolar localization of influenza A NS1 requires the presence of a C-terminal nucleolar localization signal. This nucleolar localization signal is present only in certain strains of influenza A viruses. Therefore, only certain NS1 accumulate in the nucleolus of mammalian cells. In contrast, we show that all NS1 tested in this study accumulated in the nucleolus of avian cells even in the absence of the above described C-terminal nucleolar localization signal. Thus, nucleolar localization of NS1 in avian cells appears to rely on a different nucleolar localization signal that is more conserved among influenza virus strains.
\end{abstract}

\section{Findings}

The nucleolus is a highly dynamic multifunctional subnuclear compartment [1]. It is the site of ribosomal RNA synthesis and ribosomal subunits assembly. In addition, the nucleolus is increasingly recognized as a critical regulator of many other cellular functions, including the regulation of mitosis, cell growth and response to stress [1-3]. The nucleolus is also emerging as an important target of various viral proteins [4]. Viral proteins targeting the nucleolus are for example implicated in the regulation of apoptosis, as shown with West Nile virus capsid protein, and in the regulation of viral mRNA export, as shown with human immunodeficiency virus Rev protein and with herpesvirus saimiri ORF57 protein [5-7]. However, for most viruses, consequences of viral protein localization in the nucleolus remain largely unknown $[3,4]$.

The non-structural 1 (NS1) protein of influenza A viruses NS1 is a multifunctional protein, known to interact with and modify the function of many cellular proteins, thereby creating a cellular environment favouring virus replication [8]. Recently, a nucleolar localization signal (NoLS) has been identified in NS1 [9]. This NoLS targets NS1 to the nucleolus of mammalian cells. Presently, the role of the nucleolar localization of NS1 in the viral cycle is unknown. One can speculate that NS1 proteins targeting the nucleolus of mammalian cells could modify the functions of nucleolar proteins. The

\footnotetext{
* Correspondence: rvolmer9@gmail.com
'INRA, UMR 1225, Ecole nationale vétérinaire de Toulouse, F-31076 Toulouse,

* Correspondence: rvolmer9@gmail.com
'INRA, UMR 1225, Ecole nationale vétérinaire de Toulouse, F-31076 Toulouse, France
}

(C) 2010 Volmer et al; licensee BioMed Central Ltd. This is an Open Access article distributed under the terms of the Creative Commons Attribution License (http://creativecommons.org/licenses/by/2.0), which permits unrestricted use, distribution, and reproduction in any medium, provided the original work is properly cited.
C-terminal basic amino acids that are present only in certain strains of influenza A viruses [9]. Thus, only certain NS1 proteins accumulate in the nucleolus of mammalian cells. Whether NS1 proteins accumulate in the nucleolus of avian cells is currently unknown.

In this study, we compared the nucleolar localization of NS1 of different influenza virus strains in mammalian and avian cells using immunocytochemistry and confocal microscopy. Experiments were done in human A549 alveolar epithelial cells and in primary embryonic fibroblasts used between passages 2 and 6, cultured from 11 days old Balb/c mouse (Mus musculus) embryos, from 14 days old Pekin duck (Anas platyrhynchos) embryos or from 12 days old chicken (Gallus gallus) embryos. Cells were infected at a multiplicity of infection (MOI) of 3 plaque forming units $(\mathrm{pfu})$ per cell $(\mathrm{MOI}=3)$ with the human influenza A/Udorn/72(H3N2) strain (designated Udorn), the human laboratory adapted influenza A/PR/8/34(H1N1) strain (designated PR8), the avian influenza A/Turkey/Italy/977/V99(H7N1) strain (designated 977) or the avian influenza A/Turkey/Italy/4426/ 00(H7N1) strain (designated 4426). At 3, 4, 6, 8 and 12 hours post-infection (hpi), cells were fixed with $4 \%$ Paraformaldehyde, permeabilized with Phosphate Buffered Saline (PBS) $0.5 \%$ Triton X-100 and incubated for one hour in PBS $0.1 \%$ Triton X-100 and 2\% Bovine Serum Albumin. Antibody incubation was performed overnight at $4^{\circ} \mathrm{C}$.

The C-terminal sequence of Udorn NS1 protein contains the basic amino acids identified by Melen et al. as 
defining the mammalian NoLS (underlined in Figure 1), whereas the other NS1 proteins lack one or more of these basic amino acids [9]. Consequently, only the NS1 of Udorn accumulated in the nucleolus of primary mouse embryonic fibroblasts (MEF) and of A549 human respiratory cells (Figure 1). NS1 proteins of the other viruses tested did not accumulate in the nucleolus of mammalian cells irrespective of the time post-infection (Figure 1). By contrast, the NS1 of all viruses used in this study accumulated in the nucleolus of primary duck embryonic fibroblasts (DEF) and primary chicken embryonic fibroblasts (CEF) at $4 \mathrm{hpi}$ (Figure 1). Thus, all NS1 proteins tested have an amino acid sequence forming a functional NoLS in avian cells. In addition, our results show that the amino acids required to target NS1 to the nucleolus of avian cells differ from the amino acids required to target NS1 to the nucleolus of mammalian cells.

Then, we verified that NS1 targets the nucleolus in vivo. We infected two-week old Pekin ducks orally with

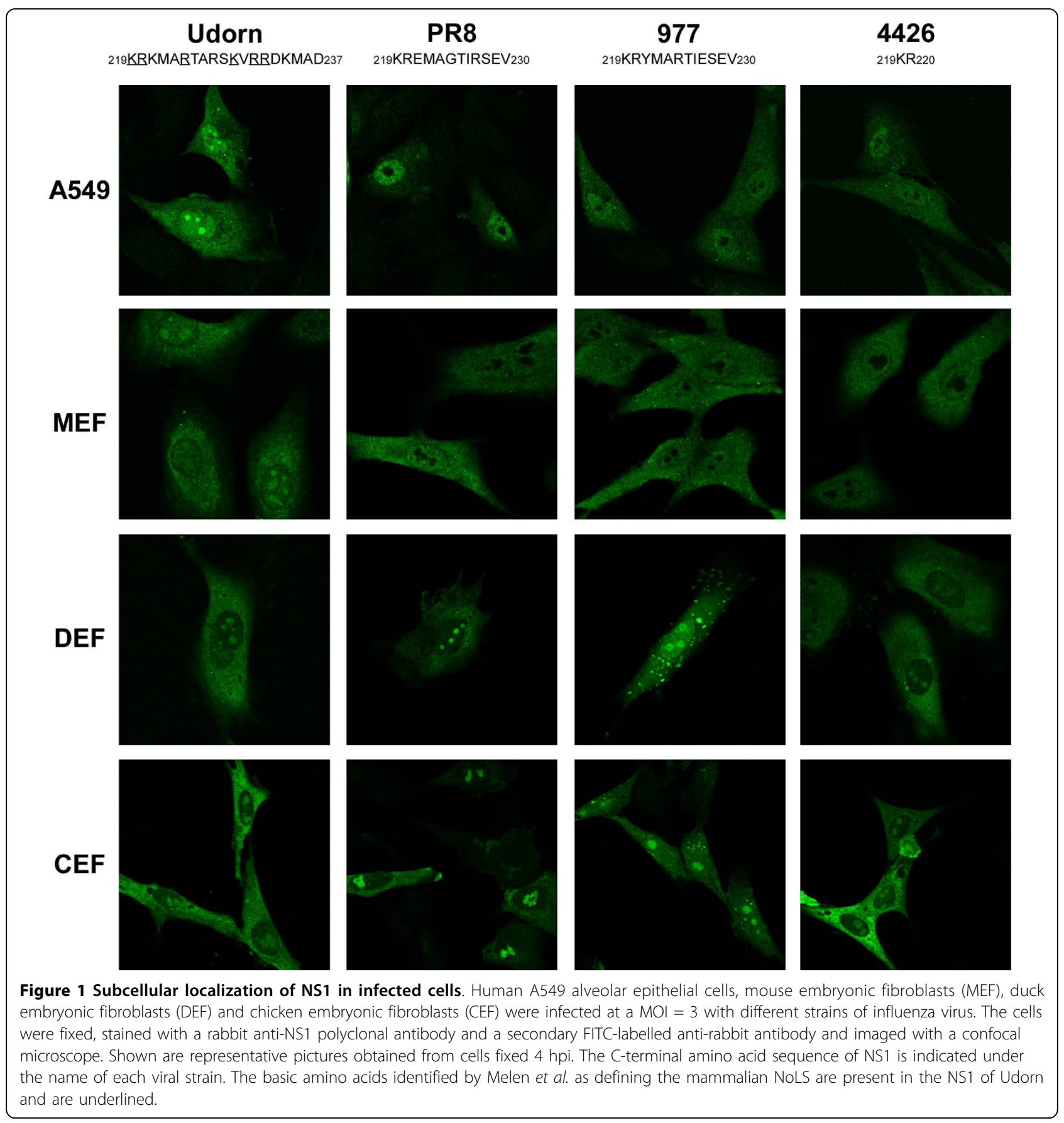


$10^{7} \mathrm{pfu}$ of the 977 virus. Previous experiments performed with this virus had shown that the ileum and the colon were the major sites of virus replication (our unpublished observation). Immunohistochemical staining of $3 \mu \mathrm{m}$ paraffin embedded ileal sections with a rabbit polyclonal anti-NS1 antibody (Figure 2) revealed the presence of viral antigens in enterocytes 6 days post-infection. Anti-NS1 antibodies detected with a peroxidase-coupled secondary antibody revealed with diaminobenzidine stained the cytoplasm and subnuclear structures, corresponding to nucleoli (Figure 2). Thus, the subcellular localization of NS1 in vitro is consistent with its nucleolar localization in duck intestinal epithelial cells.

Viral infections can lead to changes in the nucleolar morphology, likely caused by virus-induced disruption of nucleolar functions, as shown for the infectious bronchitis coronavirus and for the herpes simplex virus 1 $[10,11]$. We therefore analyzed whether nucleolar localization of NS1 modified the expression pattern of nucleophosmin (NPM), a nucleolar protein that localizes to the granular centre of the nucleolus [3]. We performed a time course analysis of the intracellular localization of NS1 and NPM (Figure 3) in DEF infected at a MOI $=3$ with either the 977 or the Udorn viruses. In DEF, NS1 of both viruses colocalized with NPM (Figure 3). Nucleolar localization of NS1 was visible $3 \mathrm{hpi}$ and was maximal between 4 and 6 hpi (Figure 3). Nucleolar accumulation declined starting $6 \mathrm{hpi}$. The intensity of nucleolar NS1 staining eventually became indistinguishable from the nucleoplasmic NS1 staining between 8 and $12 \mathrm{hpi}$. In addition, we detected bright cytoplasmic foci of NS1 in DEF infected with the 977 virus (Figure $1 \& 3)$. These foci were reminiscent of previously described virus-induced cytoplasmic inclusions that remain of uncertain identity [12]. No apparent change in the pattern of NPM expression was observed in DEF infected with the 977 virus. By contrast, starting 12 hpi, faint NPM staining could be detected in the nucleoplasm of Udorn infected cells, suggesting that a fraction of NPM is displaced from the nucleolus to the nucleoplasm following infection. Increased levels of NPM in the nucleoplasm, as well as ring-like NPM staining pattern were detected in about $50 \%$ of Udorn infected cells at $12 \mathrm{hpi}$. Interestingly, changes in NPM staining pattern has also been observed following infection with the coronavirus infectious bronchitis virus whose nucleocapsid protein targets the nucleolus [10]. In DEF infected with Udorn, changes in the nucleolar morphology appeared between 8 and $12 \mathrm{hpi}$, corresponding to a stage in the virus life cycle where cytopathic effects, such as membrane blebbing became visible (date not shown). Thus, rather than being due to a direct effect of NS1 on nucleolar functions, disruption of the nucleolar morphology in influenza virus infected cells could result from virus induced intracellular stress. Alternatively,
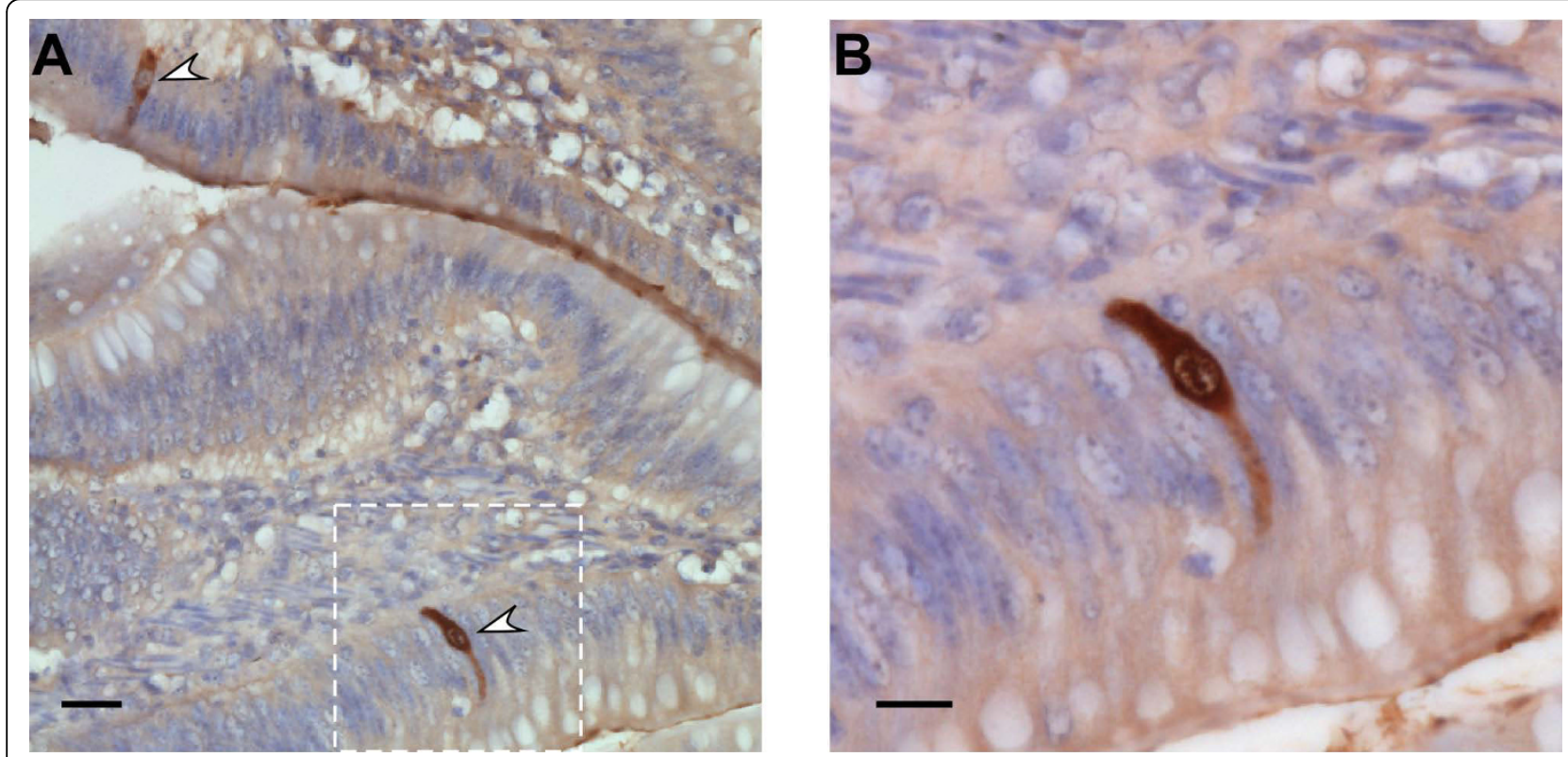

Figure 2 Subcellular localization of NS1 in duck ileal epithelial cells in vivo. A) lleum collected 6 days post-infection from a Pekin duck infected orally with $10^{7}$ pfu of the 977 virus, formalin fixed, sectioned at $3 \mu \mathrm{m}$. Immunohistochemical anti-NS1 staining detected with a peroxidase-coupled secondary antibody revealed with diaminobenzidine, hematoxylin counterstained. Arrowheads point to NS1 positive enterocytes. Scale bar $=20 \mu \mathrm{m}$. B) Magnification of the dotted region shown in panel A. NS1 staining is detected in the cytoplasm and in subnuclear structures, corresponding to nucleoli. Scale bar $=10 \mu \mathrm{m}$. 


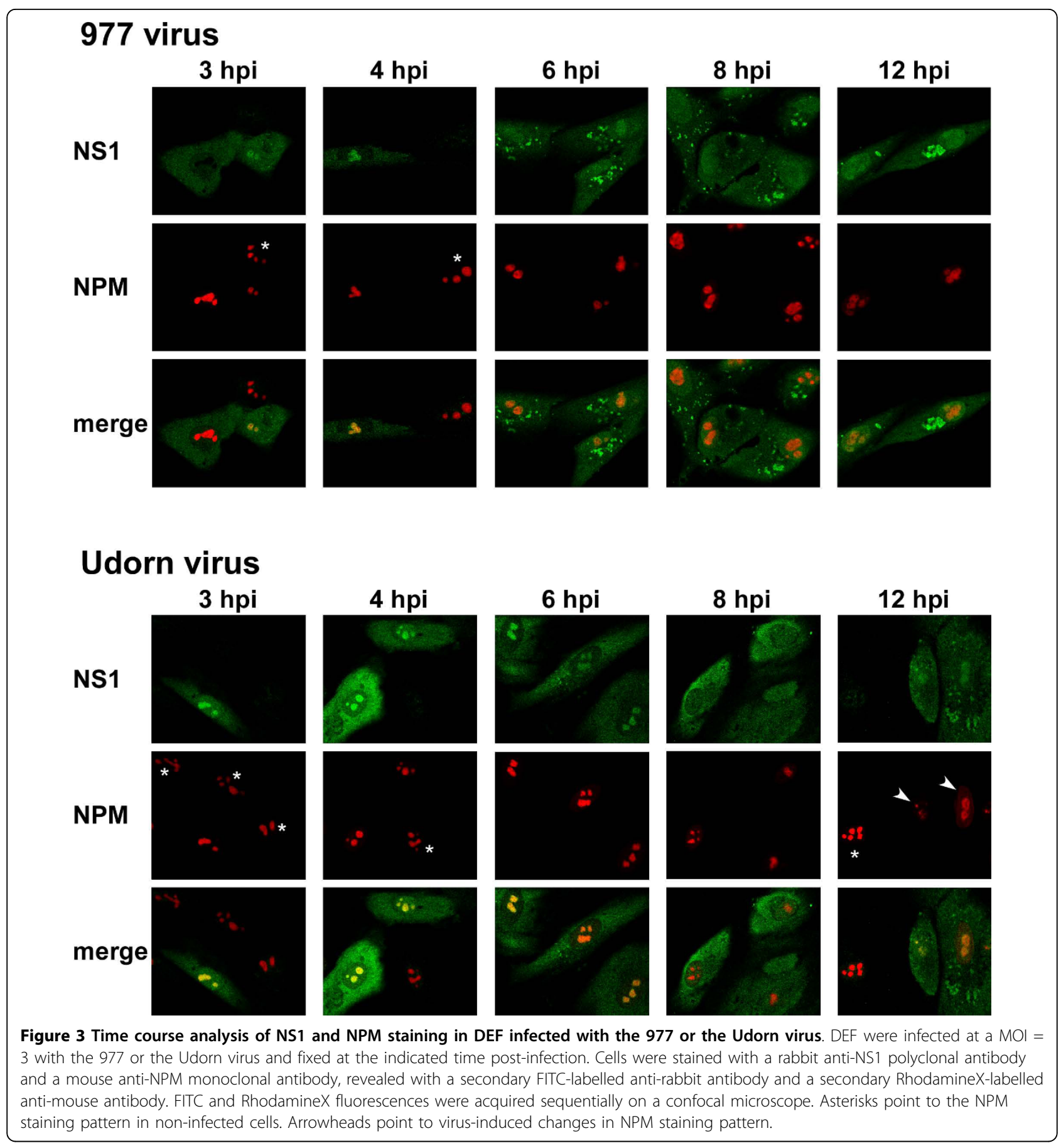

displacement of NPM from the nucleolus to the nucleoplasm could be due to an interaction of the viral ribonucleoprotein complex with NPM, as shown in MDCK cells infected with the influenza A/WSN/33 virus [13].

Presently the role of the nucleolar localization of NS1 in influenza virus cycle is unknown. In mammalian cells, nucleolar accumulation of NS1 occurs only with certain strains of influenza A viruses. As the NS1 of all viruses studied here targeted the nucleolus of avian cell, we speculate that the nucleolar localization of NS1 could be an important step during the viral cycle in avian cells. Whether, nucleolar localization of NS1 contributes to virulence is currently unknown. Valuable information would certainly be obtained by studying the phenotype of a reverse genetics engineered virus lacking a functional NoLS. In order to perform such studies in avian cells, the avian NoLS needs to be identified. Our results show that the avian NoLS relies on an amino acid 
sequence that is present in all the influenza virus strains tested in this study, and thus could be conserved among most influenza virus strains.

\section{Acknowledgements}

We thank I. Capua and W. Dundon (Istituto Zooprofilattico Sperimentale Delle Venezie, Legnaro, Italy), N. Naffakh (Institut Pasteur, Paris) and R. Fouchier (Erasmus University, Rotterdam, Netherlands) for the kind gift of viruses, D. Marc (INRA, Tours, France), J. Ortin (Centro Nacional de Biotecnología, Madrid, Spain) for the kind gift of antibodies.

\section{Author details}

'INRA, UMR 1225, Ecole nationale vétérinaire de Toulouse, F-31076 Toulouse, France. ${ }^{2}$ Université de Toulouse; ENVT; UMR 1225; F-31076 Toulouse, France.

${ }^{3}$ Centre for Biomolecular Sciences, School of Biology, University of St.

Andrews, North Haugh, St. Andrews, Fife KY16 9ST, UK.

\section{Authors' contributions}

Conceived and designed the experiments: RV. Performed the experiments: RV, BMS, CV, SMS. Analyzed the data: RV, BMS, JLG. Wrote the paper: RV, BMS. All authors read and approved the final manuscript.

\section{Competing interests}

The authors declare that they have no competing interests.

Received: 19 November 2009 Accepted: 17 March 2010

Published: 17 March 2010

\section{References}

1. Boisvert FM, van Koningsbruggen S, Navascues J, Lamond Al: The multifunctional nucleolus. Nat Rev Mol Cell Biol 2007, 8:574-585.

2. Mayer C, Grummt I: Cellular stress and nucleolar function. Cell Cycle 2005, 4:1036-1038.

3. Sirri V, Urcuqui-Inchima S, Roussel P, Hernandez-Verdun D: Nucleolus: the fascinating nuclear body. Histochem Cell Biol 2008, 129:13-31.

4. HiscoX JA: RNA viruses: hijacking the dynamic nucleolus. Nat Rev Microbiol 2007, 5:119-127.

5. Boyne JR, Whitehouse A: Nucleolar trafficking is essential for nuclear export of intronless herpesvirus mRNA. Proc Natl Acad Sci USA 2006, 103:15190-15195.

6. Yang MR, Lee SR, Oh W, Lee EW, Yeh JY, Nah JJ, Joo YS, Shin J, Lee HW, Pyo S, Song J: West Nile virus capsid protein induces p53-mediated apoptosis via the sequestration of HDM2 to the nucleolus. Cell Microbiol 2008, 10:165-176.

7. Zolotukhin AS, Felber BK: Nucleoporins nup98 and nup214 participate in nuclear export of human immunodeficiency virus type 1 Rev. J Virol 1999, 73:120-127.

8. Hale BG, Randall RE, Ortin J, Jackson D: The multifunctional NS1 protein of influenza A viruses. J Gen Virol 2008, 89:2359-2376.

9. Melen K, Kinnunen L, Fagerlund R, Ikonen N, Twu KY, Krug RM, Julkunen I: Nuclear and nucleolar targeting of influenza A virus NS1 protein: striking differences between different virus subtypes. J Virol 2007, 81:5995-6006.

10. Dove BK, You JH, Reed ML, Emmett SR, Brooks G, Hiscox JA: Changes in nucleolar morphology and proteins during infection with the coronavirus infectious bronchitis virus. Cell Microbiol 2006, 8:1147-1157.

11. Lymberopoulos MH, Pearson A: Involvement of UL24 in herpes-simplexvirus-1-induced dispersal of nucleolin. Virology 2007, 363:397-409.

12. Petri T, Dimmock NJ: Phosphorylation of influenza virus nucleoprotein in vivo. J Gen Virol 1981, 57:185-190.

13. Mayer D, Molawi K, Martinez-Sobrido L, Ghanem A, Thomas S, Baginsky S, Grossmann J, Garcia-Sastre A, Schwemmle M: Identification of cellular interaction partners of the influenza virus ribonucleoprotein complex and polymerase complex using proteomic-based approaches. J Proteome Res 2007, 6:672-682.

doi:10.1186/1743-422X-7-63

Cite this article as: Volmer et al: Nucleolar localization of influenza A NS1: striking differences between mammalian and avian cells. Virology Journal 2010 7:63.

\section{Submit your next manuscript to BioMed Central and take full advantage of:}

- Convenient online submission

- Thorough peer review

- No space constraints or color figure charges

- Immediate publication on acceptance

- Inclusion in PubMed, CAS, Scopus and Google Scholar

- Research which is freely available for redistribution 